\title{
Article \\ "I'll Take the E-Scooter Instead of My Car"-The Potential of E-Scooters as a Substitute for Car Trips in Germany
}

\author{
Laura Gebhardt*, Christian Wolf and Robert Seiffert
}

German Aerospace Center (DLR), Institute of Transport Research, 12489 Berlin, Germany; c.wolf@dlr.de (C.W.); robert.seiffert@dlr.de (R.S.)

* Correspondence: laura.gebhardt@dlr.de

check for updates

Citation: Gebhardt, L.; Wolf, C.; Seiffert, R. "I'll Take the E-Scooter Instead of My Car"-The Potential of E-Scooters as a Substitute for Car Trips in Germany. Sustainability 2021, 13, 7361. https://doi.org/10.3390/ su13137361

Academic Editor: Stefano Carrese

Received: 18 May 2021

Accepted: 25 June 2021

Published: 30 June 2021

Publisher's Note: MDPI stays neutral with regard to jurisdictional claims in published maps and institutional affiliations.

Copyright: (C) 2021 by the authors Licensee MDPI, Basel, Switzerland. This article is an open access article distributed under the terms and conditions of the Creative Commons Attribution (CC BY) license (https:// creativecommons.org/licenses/by/ $4.0 /)$.
Abstract: Considering the controversial discussion about the sustainability and usefulness of escooters, in this study, we analyzed the substitution potential of e-scooters, especially with regard to car trips. Based on data from the national mobility survey in Germany (Mobility in Germany, MiD 2017), we identified trips that could be covered purely by an e-scooter. Thereby, trip length, trip purposes, weather conditions, and other influencing factors were taken into account. Our analysis showed that, in Germany, $10-15 \%$ of the motorized individual transport (MIT) trips could be made by e-scooter. Accompanied by a literature analysis, we then critically reflected on the overall potential of e-scooters and formulated recommendations for urban and transport planning.

Keywords: micro-mobility; urban mobility; e-scooter; scooter sharing; car substitution; potential analysis

\section{Introduction}

The transportation system is changing, among other things based on emerging technologies [1] such as shared micro-mobility services [2]. Electric scooter (e-scooter) sharing, which is one of these new forms of urban micro-mobility [3], has recently been introduced to many cities around the world [4,5]. Since fall 2017, the first e-scooters have been seen on the streets of some cities in California [6]. From there, e-scooters also took over the streetscape of other US cities in the following year [7], as well as the first European cities, e.g., in Scandinavia and France [5,8]. E-scooters thus represent a relatively recent phenomenon. In Germany, e-scooters were introduced in June 2019 after the government ordinance on the approval of the personal light electric vehicles regulations (German Elektrokleinstfahrzeuge-Verordnung) entered into force [9]. Since then, companies such as the US-based provider Lime, the Swedish Voi, and others have been operating in numerous German cities, expanding the portfolio of mobility services (cf. Figure 1). By the end of September 2019, there were already more than 62,000 e-scooters on German roads, about half of them in Germany's four largest cities, Berlin, Hamburg, Munich, and Cologne [10]. Because of the COVID-19 pandemic, the number of scooters was significantly lower in 2020, since all providers except TIER temporarily stopped operations.

The discussion about e-scooters has been insufficiently substantiated by scientific research to date. Numbers are still lacking on both the actual use and the potential of e-scooters, especially with regard to a possible reduction in motorized individual transport (MIT). There is some limited data available from different e-scooter providers, although it is unclear to what extent the data have been collected, evaluated, and interpreted scientifically. In addition, the data available pertains almost exclusively to inner-city areas where the services are currently provided.

The proportion of e-scooter trips in the modal split is still too small for analyses based on general mobility surveys. This would otherwise be a good basis to make differentiated statements about uses and users. The use of e-scooters has not been comprehensively investigated in any scientific large-scale survey either. The last large-scale national mobility 
survey (Mobility in Germany (MiD)) was conducted in 2017, when e-scooters did not yet exist on German roads.

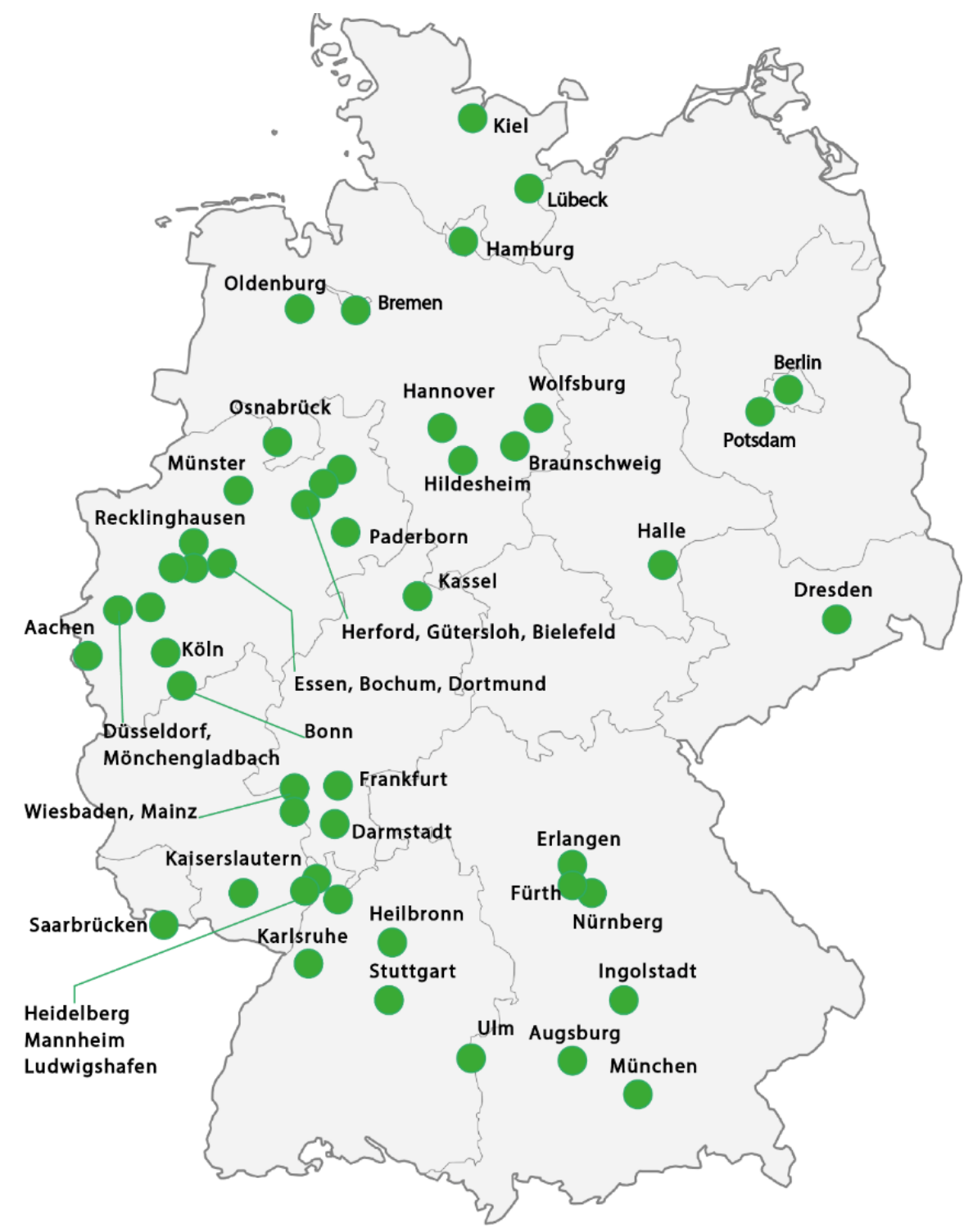

Figure 1. Overview of cities with e-scooter sharing systems (January 2021). The providers considered were Lime, Bird, TIER, Voi, Dott, and Hive. The representation can only be seen as a snapshot, because the number of providers and cities is increasing. Source: own representation, 2021.

At the moment, it is assumed that only a few car trips in Germany have been replaced by e-scooters, but detailed numbers on this are not available.

Against this background, we provide an estimation of the theoretical substitution potential of e-scooters for MIT trips in Germany, based on our own calculations and drawing on the German national mobility survey MiD 2017. Accompanied by a literature analysis, we then critically reflect on the overall substitution potential of e-scooters.

The relationship between e-scooters and public transport (PT) requires a more indepth analysis as well. A switch from PT to e-scooters might lead to a further increase in individual transport and a decrease in PT usage. Positive effects for PT are also conceivable, however. For example, e-scooters could be used as an alternative means of transport at peak times and thus could help to reduce the overcrowding of buses and trains.

E-scooters have been described as an environmentally friendly means of transport, in particular by their providers [6], because of their low land use consumption as well as their 
significantly better energy efficiency compared with conventional motorized vehicles [11]. A stated-choice experiment conducted by Baek et al. [12] showed that some users found the combination of PT and e-scooters to be more attractive than traveling by car. Assuming that short car trips would be replaced by e-scooters and that inter- and multimodal mobility behavior would be promoted in combination with PT $[13,14]$, it is hoped that the introduction of e-scooters could contribute to a reduction in MIT. The potential in terms of a feeder function is attributed to e-scooters, especially in combination with PT for connecting suburban and inner-city areas [5,11]; thus, shared e-scooters are considered a solution for the first and last mile [13] and are marketed as such [6,11]. In addition to the reduction in traffic and its negative consequences, the substitution of car trips by e-scooters could lead to a reduction in transport emissions [15]. These include emissions that impact climate change as well as those that impact inner-city air quality. Actual energy savings and environmental effects have not yet been adequately evaluated. Hollingworth et al. [16] addressed the question of sustainability of e-scooters and found that battery production, transport, and maintenance in particular lead to high $\mathrm{CO}_{2}$ emissions per $\mathrm{km}$ calculated over the life cycle. Their results do show that in the case of replacing MIT trips, a net reduction in $\mathrm{CO}_{2}$ emissions would be achieved [16]. However, more $\mathrm{CO}_{2}$ emissions are emitted when driving an e-scooter compared to more environmentally friendly modes like PT, bicycles, or travelling on foot. Therefore, the use of e-scooters in German cities is met with criticism, which is furthered by the fact that accessibility is ensured by well-developed PT, on foot and by bicycle, especially in city centers [17]. Additionally, critical scientific reports have been published on emerging land use conflicts between e-scooters and, e.g., pedestrians [18] and on traffic safety $[19,20]$. Safety issues and regulations are dealt with differently in different cities. While some municipalities adopt individual solutions, others react more cautiously [21]. At the same time, stakeholders such as the German Association of Cities (the Deutscher Städtetag) are calling for more and uniform regulations [22,23]. Thus, a heated public debate has arisen about the usefulness and sustainability of e-scooters.

With our study, we aimed to make a scientific contribution to the discussion about what substitution potential e-scooters might actually have. First, we present a systematically reviewed and structured state of current research. Here, we compiled information about the effects of e-scooter usage, as well as the patterns of use that have been observed to date (Section 2). In Section 3, we explain the methodological procedure of calculating a theoretical substitution potential of e-scooters on the basis of available mobility data (MID 2017). We then present the results of our analysis of the substitution potential of e-scooters to (a) substitute car trips and (b) substitute PT or improve access to PT, thus possibly promoting its use (Section 4). In Section 5, we discuss the results regarding the existing literature and identify the need for further research, and finally, we draw a short conclusion in Section 6.

\section{Literature Review}

A high density of demand was observed in Berlin, the capital of Germany, in inner-city areas popular with tourists when e-scooters were first introduced in Germany. It was therefore assumed that this was an early adaptation by tourists who were already familiar with e-scooters in their home countries [10]. In France, e.g., about $42 \%$ of rental scooter users are tourists and $58 \%$ are locals, according to the 6t-bureau de recherche [8].

About 10\% of trips in France can be classified as scooter strolls [8], meaning trips without a specific purpose, and thus as induced traffic, undertaken mainly by non-local users. The relatively high duration of these scooter strolls (33 min on average) increases the overall average travel time (19 $\mathrm{min})$. More than half of all trips (55\%) take less than 15 min [8]. Initial data on the average trip length with an e-scooter in Germany vary between 1.5 and $2.5 \mathrm{~km}$ [11], while Tack et al. [10] calculated the average trip length to be $1.8 \mathrm{~km}$. In the wake of the COVID-19 pandemic, it has been observed that trips have lengthened. The provider Lime states that the average distance has increased by $18 \%$ to 
just over $2 \mathrm{~km}$ [24]. It is reasonable to assume that short trips were made with e-scooters instead of PT, as they represent a contact-free mobility option.

It is noteworthy that most e-scooter rides occur on weekends in the U.S. $[25,26]$, Germany [10,27], France [8], and in Switzerland [28]. According to the 6t-bureau de recherche [8], nearly $40 \%$ of rides in the French cities studied occur on weekends alone, with nearly one-third occurring between 2 and $5 \mathrm{pm}$. The more frequent rentals on weekends, as well as the concentration of trips in central locations [10,28], suggest that these are primarily leisure trips. Furthermore, many e-scooter trips also occur on weekdays during evening hours, albeit in lower numbers $[10,25,26]$. The results of the study by Badia and Jenelius [29] also support the conclusion that e-scooters are mostly used for leisure purposes. Divided into social/entertainment and fun/recreation, leisure purposes have proportions of $40 \%$ and even more than $50 \%$ in half of the 13 cities considered [29].

Particularly high levels of weekend use have been observed in Berlin and Hamburg during good weather conditions, also suggesting e-scooter use for recreational activities. Providers indicate that the e-scooter demand in Germany is particularly declining on days with high precipitation, while cooler temperatures alone have little effect [30]. A study by Mathew et al. [31] on the impact of weather on shared electric scooter use in Indianapolis found that usage is affected more strongly by temperatures below freezing and snowfall than by rain.

The results of the survey by Krauss et al. [32] among residents of major German cities regarding e-scooter use according to trip purpose showed the highest willingness to use e-scooters for leisure trips and errands. In some cases, respondents could also imagine using an e-scooter for shopping and for parts of their commute to work. Few of the respondents could imagine using an e-scooter for their entire commute [32]. Surveys from France showed that about $20 \%$ of trips are for commuting [8]. In cities such as Denver (more than 50\%), Oslo (about 40\%), Santa Monica, and Los Angeles (about 30\%), a more frequent e-scooter use for commuting was observed [29].

With the introduction of e-scooters as a new competitor vying for public space and transport infrastructure, further conflicts occurred with pedestrians and cyclists, because of the higher demand for an already scarce space [11,29]. These conflicts mainly involve the consumption of urban space for parking $[14,18]$ and the use of e-scooters on sidewalks, bike lanes, and traffic lanes [29]. These conflicts provoke an extensive negative perception among the population [29]. In Portland and France, surveys show that e-scooter users are significantly less likely to use sidewalks when protected bike lanes are available or when permitted speeds of motorized traffic are low $[8,26]$.

In addition to raising awareness of e-scooter users for considerate behavior in road traffic, measures with regard to the parking of e-scooters are also necessary [11]. James et al. [18] found that footpaths blocked by e-scooters are perceived as such by e-scooter riders significantly less often than by other road users (21\% of e-scooter users vs. $75 \%$ of non-users). Especially in streets with high usage pressure, designated parking zones (ground markings, appropriate stands, or geo-fencing) for e-scooters can reduce these conflicts [33]. In addition, regulation of e-scooter parking, especially around PT stations, is considered to play a key role in strengthening intermodal mobility behavior [34]. Among e-scooter users in Paris, a greater willingness to respect parking regulations has been observed over time. While almost two-thirds of e-scooters were parked on sidewalks in spring 2019, this value dropped to only 3\% in fall 2020 [34]. Alongside campaigns by authorities and providers to raise user awareness of correctly parking rental e-scooters, new regulations on operation and parking procedures have been implemented by Paris authorities in collaboration with providers [34].

Studies on user groups from France and the U.S. show that e-scooter users are predominantly male, young, affluent, and with above-average education $[5,8,18,35]$. User groups of e-scooters in the U.S. and France correspond to those of early adopters of other shared mobility services [13,32]. In Germany, little is known about users of e-scooters [11], as information about user groups is not provided in detail by individual providers because 
of data protection concerns [27]. A survey on sharing services among residents of German cities found that e-scooter users are more often young, male, and employed full-time, while in terms of education level, a more heterogeneous user base was observed [32].

The potential of e-scooters as a feeder for PT, especially in peri-urban areas, cannot be fully exploited or evaluated, because of their almost exclusive use in inner cities. Pilots outside of inner cities, such as the cooperation between local PT operators and e-scooter providers in Spandau (Berlin; since December 2020) [36] and in two outer districts of Hamburg (since July 2019) [37], are an exception. The positive results of the Hamburg pilot suggest that e-scooters can certainly contribute to sustainable mobility as a mode for the last mile if urban outskirts are included [37]. Surveys among e-scooter users of the pilot in Hamburg indicate that the location of rental stations and the difficult forward planning due to uncertain availability make the use of e-scooters for commuting unattractive, especially in the morning hours [37]. Under time pressure, e.g., during morning commutes, higher access times are an additional source of stress [12]. A lack of options for the first and the last mile, as well as dissatisfaction with existing PT options, makes users more reluctant to use PT for these trips [12]. Accepted distances to find an available rental e-scooter in Paris range from $2 \mathrm{~min}$ (acceptable for $90 \%$ ) to $5 \mathrm{~min}$ of walking (acceptable for 50\%) [34].

Survey data from the 6t-bureau de recherche [8] show that about one in four e-scooter trips in Paris is part of an intermodal trip chain, combined with PT in two-thirds of the cases. By comparison, for cycling, the proportion of intermodal trips in Paris is only $9 \%$. As advantages of shared e-scooters compared to personal bicycles, the possibility of easy and fast parking close to the station and the lack of fear of theft were named [34]. Forum bikesharing Schweiz [28] also notes that e-scooter trips are concentrated near significant PT hubs. According to Tack et al. [10], in residential areas-despite marketing as a lastmile option in peripheral locations - this can only be assumed to a limited extent, as the observed use of e-scooters is concentrated in inner cities.

The proportion of modes substituted by e-scooters shows a clear difference between US and European cities, as the former are widely dispersed and consequently more car dependent [29]. European cities, on the contrary, are more compact and dense, which is why PT represents a competitive transportation solution [29]. Overall, substitution rates of motorized vehicles by e-scooters are at least 10 percentage points higher in US cities than in European cities [29].

In a study by James et al. [18], nearly half of Washington, DC respondents reported replacing a trip in a motorized vehicle with a rental e-scooter trip, with cabs or ride services accounting for the majority. The cause of the switch from ride services to e-scooters in Washington, DC could be the observed travel time benefits of e-scooters during peak hours [7]. In a 2018 pilot project in Portland, the Portland Bureau of Transportation [26] calculated that 301,856 vehicle miles (approximately 485,790 vehicle kilometers) were replaced by e-scooter use over a 120-day period. This value was calculated using information provided by the study participants: $34 \%$ of residents and $48 \%$ of visitors reported replacing a motorized-vehicle trip by an e-scooter trip [26]. In France, however, the percentages of motorized-vehicle trips replaced by e-scooter trips were much lower $(8 \%)$ [8].

In contrast, trips by foot, bicycle, or PT were also replaced by e-scooter trips. For example, $37 \%$ of respondents in Portland [26] and 33\% in Washington, DC reported that a walking trip was substituted by an e-scooter trip [18]. In France, 30\% of users reported that their most recent e-scooter ride replaced a PT trip. An e-scooter ride is often considered more pleasant than using crowded PT. In addition, the speed of e-scooters and the possibility of direct (door-to-door) trips are seen as further advantages [8]. However, the substitution of trips made on foot by e-scooter is slightly higher, on average, in European cities than in US cities because the former are more accessible on foot [29].

In Hamburg (Germany), after the introduction of e-scooters, a decreasing number of rentals of bike-sharing services was observed compared to the previous year. In particular, directly after its introduction in July 2019, the number of rentals from Hamburg's bike-sharing service StadtRAD decreased by about 50,000 to a total of about 300,000 trans- 
actions [27]. In France, a slight modal shift from bike-sharing services ( $-9 \%)$ and the use of privately owned bicycles $(-3 \%)$ to e-scooters was observed [8]. These results illustrate that e-scooters compete more with environmentally friendly modes for trips with similar characteristics [29]. In European cities, the proportion of eco-friendly modes substituted by e-scooters is up to $80 \%$ [29]. Nevertheless, only $6 \%$ of respondents in France used PT less frequently [8]. Even with high use frequencies of e-scooters, the overall impact on the modal split proportions of PT and walking is expected to be low [8].

There are limited data available from different e-scooter providers, although it is unclear to what extent the data have been collected, evaluated, and interpreted scientifically. The non-transparent access to booking data, also due to laws governing data protection and data security [11], presents a challenge in the evaluation of e-scooters. Existing studies and booking data address either usage patterns or user groups and often lack a detailed and combined analysis of vendor data and scientific surveys regarding the integration of e-scooters into everyday mobility behavior. As a result, few conclusions can be drawn about the use of e-scooters by the trip purpose of certain user groups (e.g., tourists for leisure trips). Thus, the context of e-scooter use (user group, trip purpose, trip length, other trips with other modes, etc.) is rarely comprehensively represented, which results in an isolated picture of e-scooter usage. Therefore, further analyses using provider data and in-depth scientific surveys on e-scooter usage and substituted modes, as well as analysis of the integration of e-scooters into everyday mobile life, are necessary.

\section{Materials and Methods}

This study aimed to estimate the theoretical substitution potential of e-scooters for MIT trips as well as PT and feeder trips. It was based on the Germany-wide representative survey Mobility in Germany (MiD), which is conducted approximately every 5 years and most recently in 2017 [38,39]. MiD 2017 contains data on 960,619 trips, collected between 2016 and 2017-thus from a year in which e-scooters did not yet exist on German streets. When talking about MIT trips, it should be noted that about $95 \%$ of MIT trips recorded in MiD 2017 are made by car, the remainder being motorcycles and trucks.

The data set provides a weighting factor as well as an extrapolation factor, which are based on the sociodemographic characteristics of the respondents. By including these factors, it was possible to calculate a representative image of the trips made by the residential population of Germany and even absolute numbers, e.g., to determine the potentially substitutable mileage of MIT [40]. In the following Section 3.1, we describe how we calculated the theoretical substitution potential for MIT trips. Then, we explain how we analyzed the substitution potential for PT and the potential of the e-scooter for feeder trips to PT (Section 3.2).

\subsection{Data Analysis to Estimate the Substitution Potential for MIT Trips}

To estimate the theoretical potential for e-scooter-substitutable MIT trips, we first specified the criteria that a trip must meet to be considered potentially manageable by an e-scooter (cf. Figure 2). This was done based on the findings from the literature review and based on expert knowledge. On the basis of these criteria, the total number of MIT trips in the MiD 2017 was filtered step by step until only trips that met all the requirements and thus were potentially manageable by e-scooters remained. The criteria can be divided into trip-related and person-related criteria, which are briefly described below.

A central criterion within this analysis was the trip length. Since the use of an e-scooter is unlikely over shorter distances, the lower limit of the trip length was set at $250 \mathrm{~m}$. For the upper limit, two different scenarios were calculated. In the first scenario, $2 \mathrm{~km}$ was set as the maximum value, as this corresponds to the current average length of an e-scooter trip (cf. Section 2). For the second scenario, $4 \mathrm{~km}$ was set as the maximum value, which corresponds to the average length of a bicycle trip in Germany in 2017 [39]. 


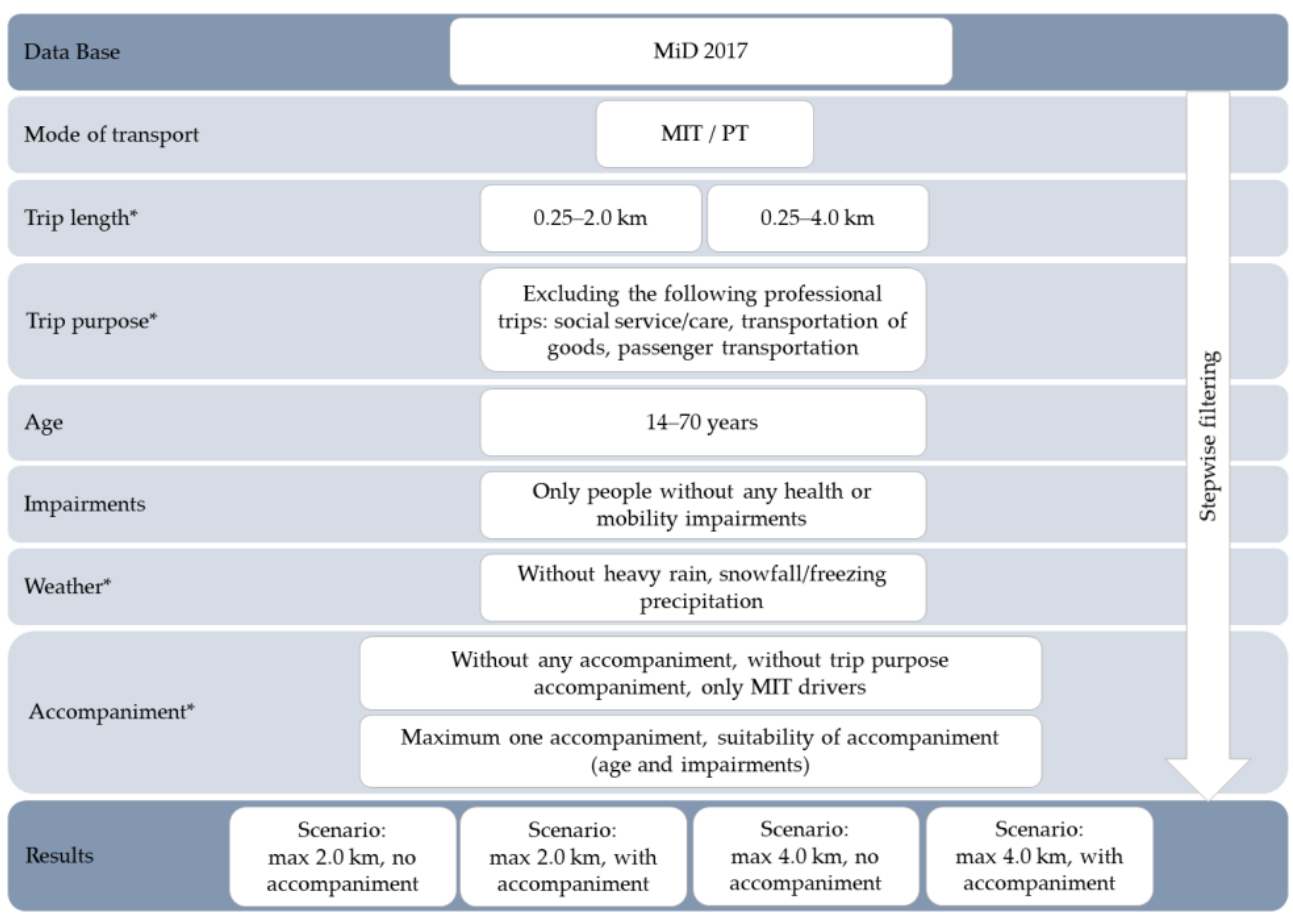

Figure 2. Overview of criteria, selected parameters, and process flow for the estimation of trips that can be made by e-scooter. Criteria marked with an asterisk were tested at the level of round trips for motorized individual transport (MIT). If a trip within a round trip was assessed as unsuitable, all other associated trips were excluded as well.

Most trips surveyed in MiD 2017 are trips that can be assigned to trip chains or, more specifically, to round trips, as they often start and end at the same point. This is an important aspect for estimating the replaceability of MIT trips by e-scooters. If, e.g., a private car is used several times within one round trip, it must be assumed that it cannot be parked at any point along the way, exchanged for an e-scooter, and then picked up again at another point for further travel or for a specific use. If the car is required for a single trip within a round trip, it will also have to be taken along on previous and subsequent trips. Normally, it will also have to be taken back to the starting point at the end of a round trip. For the substitution potential calculation, this means that if even one MIT trip does not meet the conditions, all other MIT trips of a round trip are also assessed as unsuitable. Therefore, the trip length and subsequent trip-related properties always had to be checked at the level of the round trip for all MIT trips (cf. Figure 2).

With regard to the characteristics of the people surveyed, an age limit between 14 and 70 years was set, and trips made by people who reported health impairments were assessed as unsuitable. This way, the minimum legal age for e-scooter use as well as the health suitability of the respondents were considered.

In MiD 2017, trips for both private and professional purposes were recorded. A large part of professional trips was formed by the subsample of the regular professional trips, i.e., work-related trips that are repeated in a similar manner day after day. More detailed trip purpose information is available for these trips. On the basis of this information, we excluded trips that explicitly served the transport of goods or people, as well as trips that were assigned the purpose of social services/care, as these purposes appeared unsuitable for e-scooter use.

Unfavorable weather conditions make a trip with an e-scooter much less attractive (cf. Section 2). Therefore, trips were also excluded when it was known that heavy rain or snowfall prevailed on the survey day.

A challenge in the estimation was the fact that many of the surveyed trips were not made alone and that the traveler was accompanied by one or more persons. We assessed 
a substitution of MIT trips with several passengers by single e-scooter trips as unlikely, but as a compromise, we calculated two different scenarios. In the first scenario, trips made accompanied by someone as well as trips made alone but that served to accompany someone were excluded. These included, e.g., outward or return trips of round trips for the purpose of bringing or picking up children and adolescents from kindergarten or school. In the second scenario, a maximum of one accompanying person and also the purpose of accompaniment were permitted. Trips made with an accompanying person who could be identified as unsuitable for e-scooter use because of age or impairments were excluded from the analysis.

A further challenge in the analysis was missing information. In MiD 2017, not all trips were recorded at the same level of detail; in addition, information was missing for some trips for various reasons. However, a lack of information about a criterion means that trips cannot be evaluated as unsuitable on the basis of that criterion. These criteria included weather conditions and accompaniment. Weather conditions were collected only for a person's first trip on the survey day. Nevertheless, to obtain a realistic distribution of weather conditions for most trips, we assigned the weather on the first trip to all other trips on the same day.

With regard to missing information, regular professional trips have to be mentioned. These types of trips account for two-thirds of professional trips but were generally surveyed in less detail. No information about the criterion of accompaniment was collected; therefore, excluding professional trips on the basis of this criterion was hardly possible. However, since these trips are important for a representative estimation of the total potential, they were included in the analysis, and the problem is revisited in the interpretation of the results.

\subsection{Substitution of PT Trips and the Potential of E-Scooters as a Feeder for PT}

The procedure for calculating the PT substitution potential is largely similar to the one described for MIT substitution, with one exception: for the PT substitution potential, it is not necessary to consider the level of round trips. Unlike in the case of the use of MIT, where the decision in favor of a vehicle at the beginning of a round trip usually implies that the vehicle must be taken along the entire round trip (cf. Section 3.1), it is possible to switch from PT to an alternative mode at any time.

To analyze the potential of e-scooters as a feeder for PT, we used the stage survey sample of MiD 2017. In MiD 2017, trips were itemized by stages. Information about 11,000 trip stages is available for 4465 trips. For our analysis, we selected trips stages that were prior to, between, or subsequent to stages on which PT was used. These stages can be described as feeder stages (hereinafter also referred to as feeder trips). The following procedure was similar to the determination of the MIT substitution potential: feeder trips were filtered according to the trip length as well as the respondents' age and impairments. The weather and accompaniment factors could not be considered here because the stage data set does not provide this information.

\section{Results}

Existing mobility data (MiD 2017) show that, in Germany, almost 30 million trips of less than $2 \mathrm{~km}$ and another 25 million trips of less than $4 \mathrm{~km}$ are made by MIT every day [41]. In this section, we present how many of these trips can potentially be covered by an e-scooter (Section 4.1) and how many PT trips and PT feeder trips (Section 4.2) can be replaced by an e-scooter trip.

\subsection{Substitution Potential for MIT Trips}

Around $57 \%$ of all daily trips in Germany are made by MIT. These trips were set as the basis for the calculation shown in Figure 3. Considering the criteria introduced in Section 3 , the figure shows how many of the MIT trips can be replaced by e-scooter trips within the scenario of unaccompanied trips under $4 \mathrm{~km}$. Of all daily MIT trips, $35.6 \%$ were in 
a range between $250 \mathrm{~m}$ and $4 \mathrm{~km}$, and $28.2 \%$ were round trips within which no single trip was longer than $4 \mathrm{~km}$. With regard to further criteria of trip purpose, individual age, health impairments, weather conditions, and (in this scenario) lack of accompaniment, the analysis resulted in a total potential of around $10.1 \%$ of all MIT trips that could, at least theoretically, be made by an e-scooter.

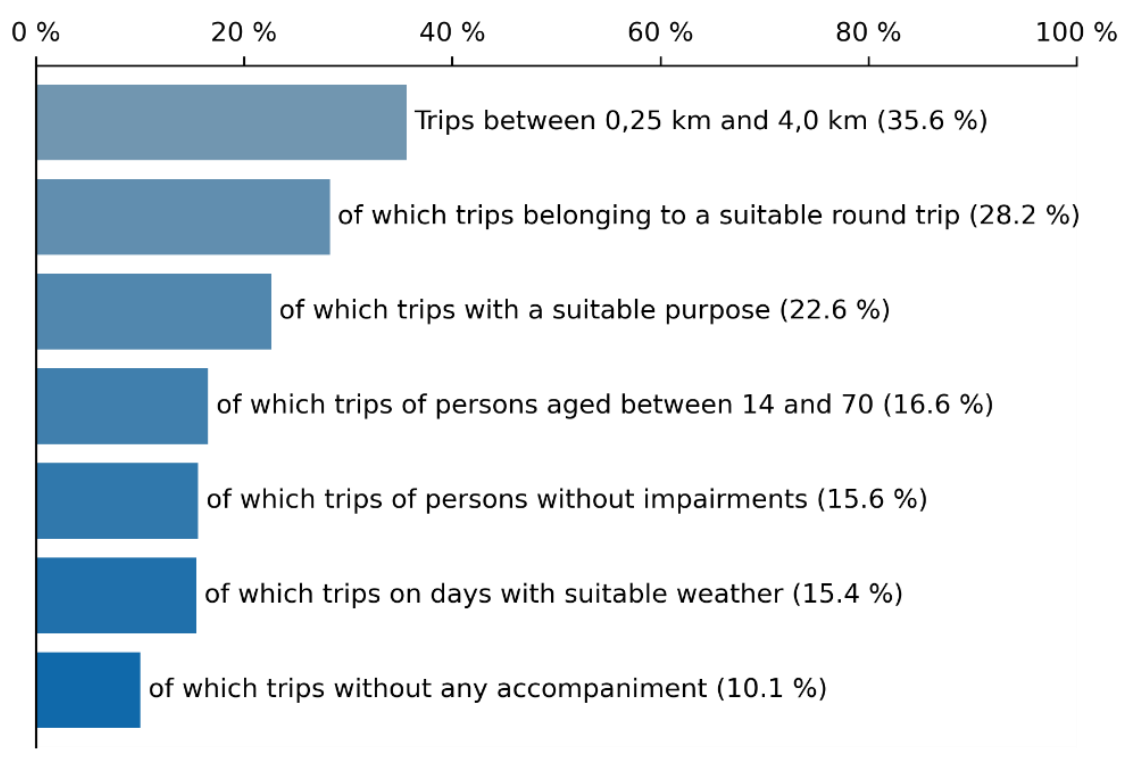

Figure 3. Substitution potentials for MIT trips resulting from step-by-step filtering (based on Mobility in Germany (MiD) 2017).

Expressed in absolute values, this corresponds to around 14.8 million daily trips and a transport performance of around 31.9 million $\mathrm{km}$. If trips made in the company of another person are also included, the maximum potential increases to $14.7 \%$ (cf. Table 1). Using this calculation for trips under $2 \mathrm{~km}$ results in a substitution potential of $4.8 \%$ to $6.8 \%$ of all MIT trips.

Table 1. Substitution potential for motorized individual transport (MIT) trips of 0.25 to $2.0 \mathrm{~km}$ and 0.25 to $4.0 \mathrm{~km}$ (based on Mobility in Germany (MiD) 2017).

\begin{tabular}{cccc}
\hline Trip Length & Accompaniment & $\begin{array}{c}\text { Substitution Potential for } \\
\text { MIT Trips of the } \\
\text { Distance Mentioned }\end{array}$ & $\begin{array}{c}\text { Substitution } \\
\text { Potential } \\
\text { for All MIT Trips }\end{array}$ \\
\hline \multirow{2}{*}{0.25 to $4.0 \mathrm{~km}$} & $\begin{array}{c}\text { Without } \\
\text { Accompaniment }\end{array}$ & $28.2 \%$ & $10.1 \%$ \\
\cline { 2 - 4 } & $\begin{array}{c}\text { One Person } \\
\text { Maximum }\end{array}$ & $41.7 \%$ & $14.7 \%$ \\
\hline \multirow{2}{*}{0.25 to $2.0 \mathrm{~km}$} & \begin{tabular}{c} 
Without \\
Accompaniment \\
\cline { 2 - 4 }
\end{tabular} & $\begin{array}{c}\text { One Person } \\
\text { Maximum }\end{array}$ & $25.6 \%$ \\
\hline
\end{tabular}

On the basis of the scenario without accompaniment and a maximum trip length of 4 $\mathrm{km}$, the distribution of the substitution potential by region, trip purpose, and respondent's age are examined in more detail next.

\subsubsection{Regional Distribution}

Using the extrapolation factor included in MiD 2017, the absolute numbers of substitutable trips were calculated for the scenario of $4 \mathrm{~km}$ without accompaniment. Table 2 
shows the number of substitutable trips in relation to all MIT trips by spatial type. For differentiation, the spatial type RegioStaRGem 5 was used. RegioStaRGem5 assigns municipalities in Germany to five different spatial types and is part of the Regional Statistical Spatial Typology (RegioStaR) of the Federal Ministry of Transport and Digital Infrastructure (BMVI) [42].

Table 2. Substitution potential for MIT trips by spatial type (based on MiD 2017).

\begin{tabular}{cccc}
\hline Spatial Type (Regiostargem5) & Total Trips & Substitutable Trips & Proportion \\
\hline Metropolis & $18,322,223$ & $1,399,696$ & $7.6 \%$ \\
\hline Regiopolis, Large City & $19,158,112$ & $1,975,820$ & $10.3 \%$ \\
\hline $\begin{array}{c}\text { Central City, } \\
\text { Medium-Size City }\end{array}$ & $33,571,595$ & $3,391,709$ & $10.1 \%$ \\
\hline Urban Area & $37,753,478$ & $4,055,870$ & $10.7 \%$ \\
\hline Small Town, Village & $38,282,475$ & $3,960,839$ & $10.3 \%$ \\
\hline Total MIT Trips & $147,087,884$ & $14,783,933$ & $10.1 \%$ \\
\hline
\end{tabular}

The substitution potentials for the different spatial types are quite similar and in an order of about $10 \%$. However, the substitution potential is somewhat lower for areas of the metropolis type than for other spatial types. Since this analysis focused on short trips, and a higher proportion of short trips can be expected for metropolitan areas in particular, this result initially appears somewhat contradictory. However, one explanation might be that in metropolitan areas, MIT is used comparatively less often on trips between the set limits of $250 \mathrm{~m}$ to $4 \mathrm{~km}$. Only about 33\% of MIT trips in metropolises are within the set limits, whereas in regiopolises/large cities and central cities/medium-size cities, the value is $39 \%$ to $40 \%$, and in urban areas, it is $36 \%$. The proportion is lower in areas of the small-town/village type, at just under $31 \%$.

Although small towns or villages have the lowest proportion of MIT trips between $250 \mathrm{~m}$ and $4 \mathrm{~km}$, the potential for a switch to the e-scooter is-perhaps surprisingly-as high as in much more densely populated areas. This suggests that trip length alone is not sufficient to explain the regional differences in the calculated substitution potentials and that some of the other trip- and person-related criteria introduced in the sections above must be considered. For example, regional differences in the age structure or the distribution of different trip purposes may affect the substitution potentials calculated here. In Figure 4, the absolute values from Table 2 are put into perspective such that it is possible to draw conclusions about the spatial distribution of the total substitution potential.

The distribution of daily MIT trips in Germany by spatial type (light-blue bars) and the respective proportion of substitutable trips (dark-blue bars) are represented. Spatial types of lower density show the highest proportions of the total substitution potential, which presumably is also due to the fact that almost three quarters of all daily MIT trips are made in such areas. Metropolises as well as regiopolises/large cities only have a proportion of about a quarter of the total substitution potential but, at the same time, are places where rental services for e-scooters predominantly exist. It should, therefore, be noted that, under the assumptions made for this calculation, there is also a potential for substituting MIT trips by e-scooters outside of metropolitan areas, regional centers, and large cities. 


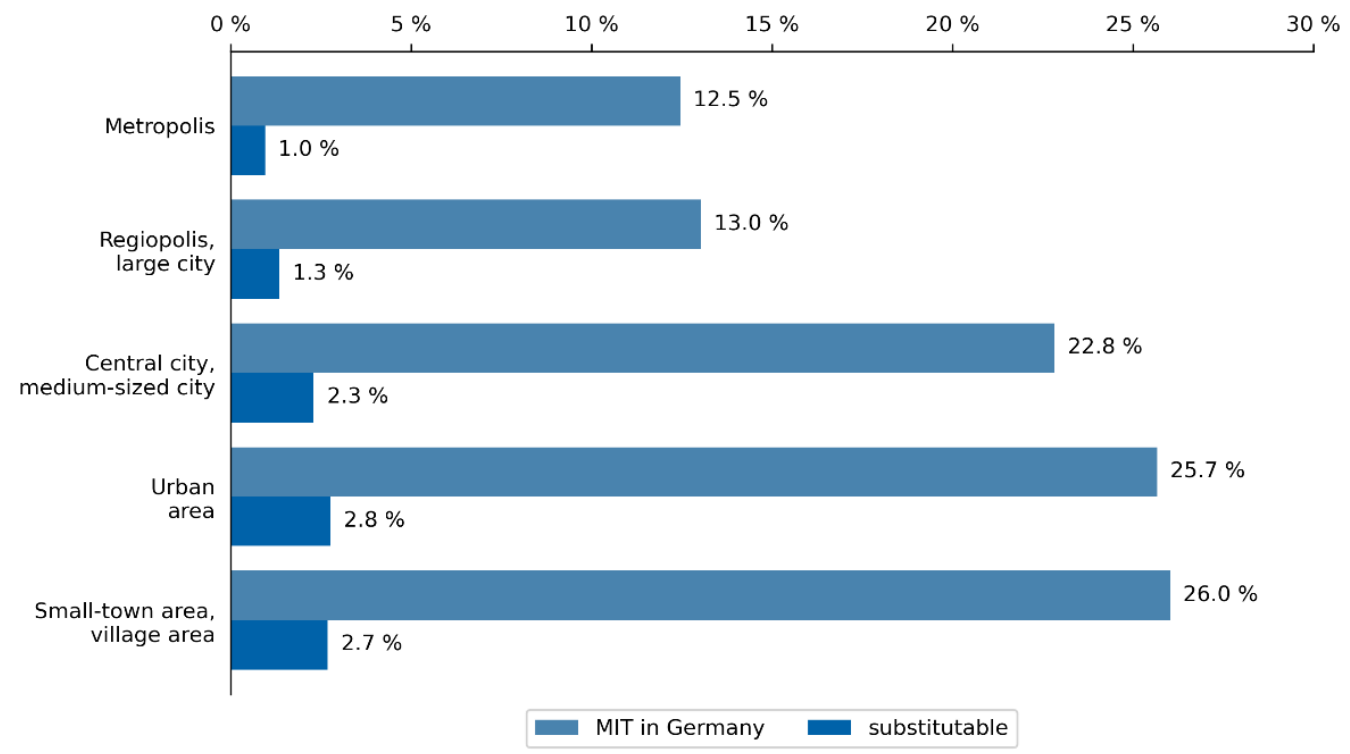

Figure 4. Total MIT trips in Germany and substitution potential by spatial type (based on MiD 2017).

\subsubsection{Trip Purposes}

The intended purpose of a trip is also important for evaluating the theoretical substitution potential of e-scooters (cf. Table 3). Regarding the distribution of the substitution potential among trip purposes, professional trips have the highest substitution potential of around 18.3\%. However, the professional trips in MiD 2017 include, to a large extent, so-called regular professional trips. Accompaniment was not surveyed for this type of trip, but it must be assumed that a specific proportion of these trips were made accompanied and that, in fact, more trips are unsuitable.

Another important point regarding the substitution potential on professional trips is the transport of items, since e-scooters provide almost no transport capabilities compared with MIT. Whether items or persons were transported on the surveyed trips could be determined by using detailed trip purposes (cf. Section 3.1). However, these were only available for the subsample of regular professional trips; thus, an assessment based on this criterion was not possible for many professional trips.

It can be assumed that with more detailed data (accompaniment, items carried), more professional trips will be assessed as unsuitable and the real substitution potential for the scenario discussed here might, therefore, be somewhat lower.

Table 3. Substitution potential for MIT trips by trip purpose (based on MiD 2017).

\begin{tabular}{cccc}
\hline Trip Purpose & Total Trips & Substitutable Trips & Proportion \\
\hline Work (Commuting) & $26,565,714$ & $2,540,916$ & $9.6 \%$ \\
\hline Professional/Business & $21,061,251$ & $3,857,702$ & $18.3 \%$ \\
\hline Education & $5,778,908$ & 129,965 & $2.2 \%$ \\
\hline Shopping & $23,102,664$ & $3,892,105$ & $16.8 \%$ \\
\hline Private Errands & $21,667,816$ & $2,207,581$ & $10.2 \%$ \\
\hline Leisure & $33,945,141$ & $2,148,728$ & $6.3 \%$ \\
\hline Accompaniment & $14,616,260$ & 0 & $0.0 \%$ \\
\hline No Information & 350,130 & 6937 & $2.0 \%$ \\
\hline Total MIT Trips & $147,087,884$ & $14,783,933$ & $10.1 \%$ \\
\hline
\end{tabular}

In addition, for the shopping trip category, a comparatively high shift potential from private motor vehicles to e-scooters was determined (around 16.8\%). This high potential 
could be explained by the fact that shopping trips are, on average, the shortest of all trips made by MIT; their average length in Germany is only $7 \mathrm{~km}$. However, in this context, just like professional trips, shopping trips must also be viewed with caution, as current e-scooter models do not offer storage space for luggage and therefore items can only be transported, e.g., in a backpack. Information about the volume of purchases is not available in MiD 2017 to an extent where it would be possible to differentiate between purchases suitable or unsuitable for transport by an e-scooter.

Trips to and from the workplace as well as trips made for private errands offer a substitution potential of around 10\% each. Short trips to work seem well suited for the use of an e-scooter, as they are frequently made without company or luggage. Leisure trips and trips that serve to reach school or another educational institution have lower substitution potentials. These trips are often made accompanied. For example, students and trainees often travel as passengers in an adult's private vehicle to their educational institution. This is one reason the substitution potentials for these trips are comparatively low, because in the scenario presented here, only trips made by self-driving MIT users are considered substitutable. With an average length of $21 \mathrm{~km}$, leisure trips are also the longest MIT trips in Germany, ahead of educational, work, and professional trips. Figure 5 shows the distribution of MIT trips by trip purpose (light-blue bars) and the respective proportion of substitutable trips (dark-blue bars).

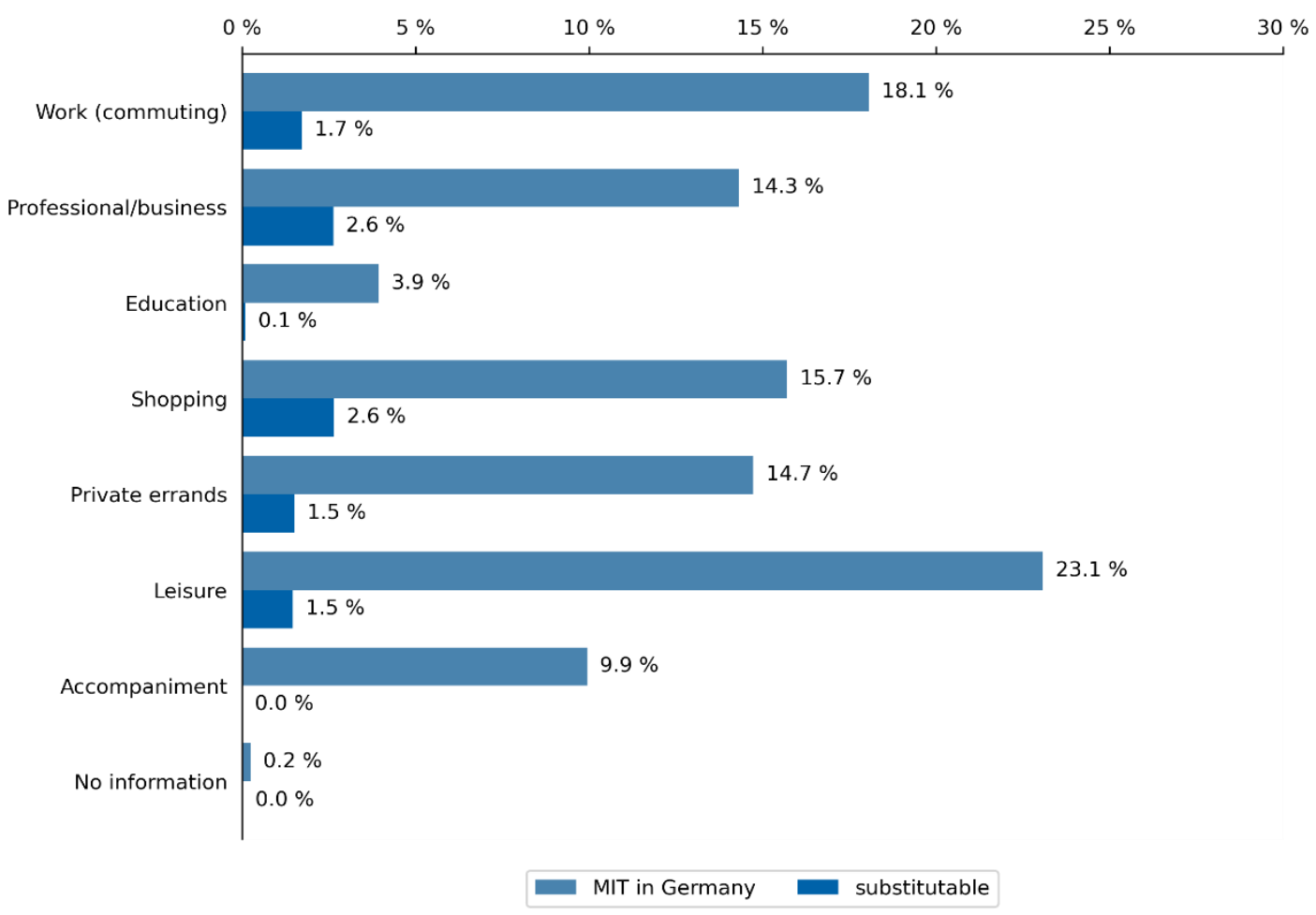

Figure 5. Total MIT trips in Germany and substitution potential by trip purpose (based on MiD 2017).

The largest proportions of the absolute potential are again found in the two categories of shopping trips and professional trips. Although leisure trips account for almost a quarter of all trips made in Germany by MIT, they had only a moderate proportion of the total substitution potential, similar to work trips and trips serving private errands. The proportion of educational trips was negligible. Trips that serve to accompany people were excluded in the scenario presented here.

\subsubsection{Age Distribution}

For our analysis, we set an age limit of 70 years for potential e-scooter usage and considered explicit health impairments, although it seems clear that, in practice, many 
elderly people may not be (or feel) in appropriate overall physical condition to safely use e-scooters. Thus, the consideration of age distribution may be helpful in adequately assessing potentials.

Table 4 shows the substitution potential within individual age groups. We used the age group classification included in MiD 2017. Because the analysis was limited to unaccompanied MIT drivers, the potential was correspondingly low within the 10-19 category, as the legal minimum age for driving without adult accompaniment is 18 years in Germany. The maximum age limit of 70 years also led to low substitution potentials in the 70-79 category.

Looking at the other relevant groups, it can be stated that the largest substitution potentials lie on MIT trips made by people above 40 . This applies to both the percentages of substitutable trips within these age groups as well as the absolute numbers of substitutable trips ( 10.5 Mio. or $71 \%$ of all substitutable trips). This theoretical potential is somewhat contradictory to the current experiences about e-scooter users being mainly young people (cf. Section 2). Moreover, these high proportions for older people should be considered with caution, because of the reason mentioned above, and therefore a full exploitation of these theoretical potentials cannot be expected.

Table 4. Substitution potential for MIT trips by respondent age (based on MiD 2017).

\begin{tabular}{cccc}
\hline Age in Groups & Total Trips & Substitutable Trips & Proportion \\
\hline $0-9$ & $10,645,825$ & 0 & $0.0 \%$ \\
\hline $10-19$ & $8,424,541$ & 378,622 & $4.5 \%$ \\
\hline $20-29$ & $16,061,816$ & $1,656,727$ & $10.3 \%$ \\
\hline $30-39$ & $21,482,346$ & $1,981,376$ & $9.2 \%$ \\
\hline $40-49$ & $27,375,130$ & $3,474,603$ & $12.7 \%$ \\
\hline $50-59$ & $28,892,275$ & $4,131,719$ & $14.3 \%$ \\
\hline $60-69$ & $18,171,077$ & $2,900,817$ & $16.0 \%$ \\
\hline $70-79$ & $12,234,421$ & 216,135 & $1.8 \%$ \\
\hline 80 and More & $3,490,910$ & 0 & $0.0 \%$ \\
\hline No Information & 309,545 & 43,934 & $14.2 \%$ \\
\hline Total MIT Trips & $147,087,884$ & $14,783,933$ & $10.1 \%$ \\
\hline
\end{tabular}

\subsection{Substitution Potential for PT Trips and Potential for E-Scooters as a Feeder for PT}

The calculated substitution potential for PT trips was similar to that for MIT trips. For trips up to a distance of $4 \mathrm{~km}$, the substitution potential was $45.5 \%$ (unaccompanied) to $55.4 \%$ (with accompaniment), which corresponds to a proportion of $11.6 \%$ to $14.1 \%$ of all PT trips (cf. Table 5). Similarly, for trips up to $2 \mathrm{~km}$, the substitution potential was $47.1 \%$ to $56.9 \%$, which accounts for $4.9 \%$ to $6.0 \%$ of the total traffic volume in PT.

Just as for MIT, spatial differences and differences by trip purpose and by age were examined for the scenario of $4 \mathrm{~km}$ without accompaniment. With regard to the spatial distribution of the substitution potential, there is a notable gap between urban and rural areas: metropolises, regiopolises, and large cities offer a substitution potential of $14.0 \%$ to $15.6 \%$, whereas areas lower in density only reach a substitution potential of $5.4 \%$ to $9.5 \%$. This could be because PT trips in lower-density areas are longer, on average, making them less suitable for e-scooter use.

The distribution of substitution potentials in terms of trip purposes hardly differs from that of MIT. Most of the substitution potential was seen in professional $(22.1 \%)$ and shopping $(20.7 \%)$ trips. Commuting to work $(11.8 \%)$ and private errands $(12.4 \%)$ showed a moderate substitution potential, followed by leisure purposes $(8.6 \%)$ and trips to reach educational institutions (6.5\%). 
Table 5. Substitution potential for public transport (PT) trips from 0.25 to $2.0 \mathrm{~km}$ and 0.25 to $4.0 \mathrm{~km}$ (based on MiD 2017).

\begin{tabular}{|c|c|c|c|}
\hline Trip Length & Accompaniment & $\begin{array}{l}\text { Substitution Potential for } \\
\text { PT Trips of the } \\
\text { Distance Mentioned }\end{array}$ & $\begin{array}{c}\text { Substitution } \\
\text { Potential } \\
\text { for All PT Trips }\end{array}$ \\
\hline \multirow{2}{*}{0.25 to $4.0 \mathrm{~km}$} & $\begin{array}{c}\text { Without } \\
\text { Accompaniment }\end{array}$ & $45.5 \%$ & $11.6 \%$ \\
\hline & $\begin{array}{l}\text { One Person } \\
\text { Maximum }\end{array}$ & $55.4 \%$ & $14.1 \%$ \\
\hline \multirow{2}{*}{0.25 to $2.0 \mathrm{~km}$} & $\begin{array}{c}\text { Without } \\
\text { Accompaniment }\end{array}$ & $47.1 \%$ & $4.9 \%$ \\
\hline & $\begin{array}{l}\text { One Person } \\
\text { Maximum }\end{array}$ & $56.9 \%$ & $6.0 \%$ \\
\hline
\end{tabular}

Considering age, the distribution of substitution potentials was overall more even, ranging from around $14 \%$ to $16 \%$ within age classes. However, there was one exception: for the 60-69 group, the proportion was 17.4\%, and, thus, like for MIT, it still bears the highest proportion of substitutable PT trips.

While it is still unclear how to evaluate a switch from PT to e-scooters for short trips, the e-scooter is, in any case, seen as a positive contribution and complement to PT on the first and the last mile [11]. In our analysis based on MiD 2017, we calculated that $52 \%$ of the considered feeder trips hold potential for the use of an e-scooter with regard to trip length as well as the respondents' age and impairments. However, most of these trips that could potentially be made with an e-scooter would be trips currently made by walking $(85 \%)$ or biking $(8 \%)$. Only $5 \%$ of the substitutable feeder trips are trips currently made by MIT, while $2 \%$ belong to other modes. Thus, for the feeder trips considered here, e-scooters would compete with the most sustainable modes. In contrast, the potential to make a positive contribution to a sustainable transportation system by replacing MIT appears to be low.

\section{Discussion}

To the best of our knowledge, this study is the first analysis of the substitution potential of e-scooters for MIT trips in Germany. We conclude that theoretically $10.1 \%$ of all MIT trips in Germany could be replaced by e-scooters. The potential varied according to the trip purpose but also according to the type of settlement and the respondent's age. The substitution potentials of e-scooters for MIT trips in metropolitan areas in Germany (cf. Section 4.1.1) correspond approximately to the proportions of MIT trips substituted by e-scooters in Paris [8]. With regard to the spatial distribution of substitution potentials, low-density areas have a substitution potential similar to that of large cities-in fact, they are the highest when absolute numbers are considered. These results correspond with the findings presented in the literature review that a higher proportion of MIT trips is substituted by e-scooters in more sprawled cities compared with compact and densely populated cities, where PT is a competitive alternative to MIT [29].

With regard to the potential of e-scooter on feeder trips, only $5 \%$ of substitutable feeder trips are trips currently made by MIT (cf. Section 4.2). In line with the spatial distribution of the substitution potential described above, the potential for MIT substitution on feeder trips could be higher in suburban areas. In addition, the results of the pilot project in Hamburg show that extending the operational areas into the outer districts could encourage the use of e-scooters as a feeder for PT [37], the potential of which has not yet been fully exhausted. Therefore, expanding the operational areas into the outer areas of larger cities as well as establishing e-scooter sharing systems in low-density areas could increase the proportion of MIT trips substituted by e-scooter trips, although the uncertainty about the availability of e-scooters discourages their use for morning commutes [12,37]. However, because of 
the limited sample size, regionally differentiated analysis for feeder trips could not be performed in this study, and further scientific analysis is required.

Concerning the MIT substitution by trip purpose, the largest potentials were determined for professional and shopping trips. However, leisure trips accounted for a relatively small proportion of substitutable trips (cf. Section 4). This could be due to their aboveaverage length, which is why they often exceed the selected maximum length of $4 \mathrm{~km}$ (cf. Section 3). Although high proportions of e-scooter use for leisure trips are reported in the literature, these cannot be differentiated by substituted modes. In addition, the sole use of e-scooters in city centers could distort the determined shares for leisure trips. Inner-cities usually offer a large number of leisure activities, which means that leisure trips may be overrepresented compared to other trip purposes. However, the high proportion of leisure trips made by e-scooters in cities indicates that e-scooters are an attractive alternative for short leisure trips in densely populated areas, while trips that would otherwise have been made by environmentally friendly means of transport are also included $[4,25,26]$. In addition, surveys on e-scooter use include non-local users (e.g., tourists) [29], whereby the use for leisure purposes may be over-represented compared to the results of the potential analysis, which does not include tourists. This may indicate that the calculated theoretical substitution potentials for other trip purposes have not yet been exhausted and that further data are needed for a scientific analysis of the different use by spatial areas and user groups.

In general, the results of this study should be understood as theoretical maximum substitution potentials based on criteria related to the suitability of trips and people. A major limitation of the used approach results from the availability of data. Information on the transport of items was not sufficiently available in the data set used, nor was information on the accompaniment for professional trips. This would require further research, particularly to more accurately assess the substitution potential for MIT trips given the limited transport capabilities of e-scooters. In addition, a further in-depth analysis considering the substitution potentials for professional trips could be helpful, as these are subject to different conditions than private trips (e.g., time pressure, use of company cars). Generally, further comparable scientific analyses for other countries and further spatial differentiation are desirable.

Whether people will actually choose to use e-scooters instead of MIT in practice also depends on more individual factors (e.g., individual (mode) preferences, perceived safety/ease of use). For example, the high substitution potentials for professional and shopping trips will hardly be practically realizable, as will the high substitution potential for elderly people. However, the general conditions of a leisure trip within city centers (e.g., low time pressure) seem suitable for the use of e-scooters.

Concerning the sustainability of e-scooters, e-scooters compete with other eco-friendly transport modes for many trips because of similar trip characteristics. E-scooters are also perceived as fast, fun, and more convenient than PT, and they offer door-to-door travel options as well [8]. The results of our analysis of the potential use of e-scooters for feeder trips also show that the greatest substitution potential appears to be on trips that are currently made primarily on foot or by bicycle. This is also reflected in the high proportions of eco-friendly transport trips substituted by e-scooter trips in general $[8,29,34]$ and the declining numbers of bike-sharing, e.g., in Hamburg [27].

Given that e-scooters contribute to higher $\mathrm{CO}_{2}$ emissions compared to other environmentally friendly alternatives [16], substitution of these means of transport should be viewed critically. However, an extrapolation of survey results to the Paris population shows that at the collective scale, the impact of free-floating e-scooters on the modal proportions of walking and PT is extremely marginal [8] and the relieving of PT by e-scooters during peak hours might also enhance the attractiveness of PT. In addition, micro-mobility services such as e-scooters can have the advantage of a reduction in travel time compared with MIT on some trips during rush hours [7], encouraging some users to use e-scooters on these trips and thus helping reduce road congestion. Additionally, e-scooters, as a noise-free mode of transportation without local greenhouse gas emissions, can contribute to a more 
sustainable transportation system by emitting fewer greenhouse gases compared with MIT [16]. According to Hollingsworth et al. [16], a total of 93\% of e-scooter emissions are attributable to manufacturing (esp. that of the battery) (50\%) as well as transport and maintenance $(43 \%)$. However, there is a need for further research especially on energy saving and other environmental impacts. Until now, emissions and other parameters such as lifetime and mileage can only be estimated, but the availability of data that can serve as a basis is limited [15,16]. In addition, future scenario calculations should consider the plans of providers to make operation more sustainable, e.g., by using e-scooters with replaceable batteries and an extended life span [30]. The former allows batteries to be replaced on site, eliminating the need to collect e-scooters for charging operations in large vans and allowing e-bikes to be used for replacement services [30]. Further research is needed regarding the question whether greenhouse gas emissions from the transportation sector including e-scooters decrease or increase because of the replacement of walking, cycling, and PT trips by e-scooters.

For e-scooters to contribute to strengthening intermodal mobility behavior and reducing MIT, in addition to expanding the operational areas, a high-quality PT service and sufficient bicycle infrastructure are needed. The reason is that e-scooter users prefer riding on (protected) bike lanes, especially on high-speed streets, and otherwise evade to sidewalks [8,26], which leads to further conflicts of use. In addition, city officials and e-scooter providers need to regulate e-scooter parking to facilitate easy transfers to PT without causing further conflicts with pedestrians [34]. Therefore, the redistribution of urban and road space, especially in densely populated areas with high usage pressure, would reduce conflicts among particularly vulnerable road users (pedestrians, cyclists, and also e-scooter users) $[18,19,34]$.

Considering the results of the potential analysis as well as the literature review, here are a few recommendations for urban and transport planning (some of our findings confirm the results of earlier studies):

1. To fully evaluate the potential of e-scooters, more and large-scale scientific research is needed. A scientifically solid database should be generated so that usage patterns, effects, risks, etc., can be evaluated.

2. To assess the potential of e-scooters as a feeder for PT, testing and evaluating escooters outside the inner-city areas of large cities are needed. Initial pilot studies, such as those on the outskirts of Hamburg [37] or Berlin, show that the e-scooter could possibly act as a supplement to PT here.

3. To overcome the current introduction strategies that do not foresee an integration of the new mode into the existing PT system (but rather a co-existence of both systems), e-scooter and PT providers should work together [21].

4. Experiences from other cities (e.g., Paris [34]) show that the creation of infrastructures and regulations minimizes conflicts with e-scooters. Therefore, cities should focus on optimizing deployment in collaboration with vendors. The usage patterns and times presented should be an impetus for e-scooter providers to review their operational strategies and for city planners to develop effective policy guidelines on parking over the course of the day, weekends, and events [7].

5. Detailed conflict and accident analyses with sufficient data would help identify the sources of danger and, if necessary, eliminate them.

6. The introduction of mandatory rules can help avoid conflicts and increase safety. This, in turn, could improve the image of e-scooters and increase their acceptance.

7. The introduction of a new mode of transportation challenges municipal authorities to discuss the (re)distribution of urban as well as street space.

\section{Conclusions}

With the introduction of e-scooters, hopes were expressed that they would contribute to the desired transformation towards sustainable, multimodal mobility. The results of this study show that there is a substitution potential for MIT trips by e-scooters, especially 
in low-density areas. Providing adequate spatial infrastructure (space to ride and park) and linking e-scooters with PT, especially in suburban and extra-urban areas, can lead to e-scooters contributing to a sustainable transport system. Currently, there is no scientific evidence that e-scooters alone will accelerate the transformation of the transportation system. Shared e-scooters have the potential to be a puzzle piece of a multimodal, sustainable transportation system. However, this will only be true if the potential applications identified in this study (e.g., areas of application, purposes) are used.

Our data and literature review showed that little scientific knowledge on the topic is available. As the e-scooter is still a new phenomenon, numbers on ridership, actual use, and potential, e.g., with regard to a reduction in MIT, are lacking. There is limited data available from different e-scooter providers, although it is unclear to what extent the data have been collected, evaluated, and interpreted scientifically. The only data available pertain almost exclusively to inner-city areas where the services are provided. Furthermore, the available booking data provide an isolated picture of e-scooter use. This is because they do not show the embedding of an e-scooter trip in trip chains and provide little information about the mobility routines of e-scooter users. To fully evaluate the potential of e-scooters, more and large-scale scientific research is needed.

Author Contributions: Conceptualization, L.G.; methodology, R.S. and L.G.; formal analysis, R.S. and C.W.; writing — original draft preparation, L.G. and C.W.; writing—review and editing, R.S., L.G. and C.W.; visualization, C.W. and R.S.; supervision, L.G.; project administration, L.G.; funding acquisition, L.G. All authors have read and agreed to the published version of the manuscript.

Funding: This research was funded by the German Aerospace Center (DLR).

Institutional Review Board Statement: Not applicable.

Informed Consent Statement: Not applicable.

Data Availability Statement: Not applicable.

Acknowledgments: The authors gratefully acknowledge Daniel Krajzewicz and Rita Cyganski for the valuable exchange in the design of the study and Rebekka Oostendorp for the proofreading.

Conflicts of Interest: The authors declare no conflict of interest.

\section{References}

1. Shaheen, S.; Totte, H.; Stocker, A. Future of Mobility White Paper. 2018. Available online: https://escholarship.org/uc/item/68 g2h1qv (accessed on 17 May 2021).

2. Kamargianni, M.; Li, W.; Matyas, M.; Schäfer, A. A critical review of new mobility services for urban transport. Transp. Res. Procedia 2016, 14, 3294-3303. [CrossRef]

3. Caspi, O.; Smart, M.J.; Noland, R.B. Spatial associations of dockless shared e-scooter usage. Transp. Res. Part D Transp. Environ. 2020, 86, 102396. [CrossRef] [PubMed]

4. Hosseinzadeh, A.; Algomaiah, M.; Kluger, R.; Li, Z. E-scooters and sustainability: Investigating the relationship between the density of E-scooter trips and characteristics of sustainable urban development. Sustain. Cities Soc. 2021, 66, 102624. [CrossRef]

5. Bieliński, T.; Ważna, A. Electric Scooter Sharing and Bike Sharing User Behaviour and Characteristics. Sustainability 2020, 12, 9640. [CrossRef]

6. Kaufman, S.M.; Buttenwieser, L. The State of Scooter Sharing in United States Cities. 2018. Available online: https: / /wagner.nyu. edu/files/faculty/publications/Rudin_ScooterShare_Aug2018_0.pdf (accessed on 17 May 2021).

7. McKenzie, G. Urban mobility in the sharing economy: A spatiotemporal comparison of shared mobility services. Comput. Environ. Urban Syst. 2020, 79, 10. [CrossRef]

8. 6t-Bureau de Recherche. Uses and Users of Free-Floating Electric Scooters in France 2019. Available online: https:/ /6-t.co/en/ free-floating-escooters-france/ (accessed on 17 May 2021).

9. Bundesregierung. Verordnung Über die Teilnahme von Elektrokleinstfahrzeugen am Straßenverkehr (ElektrokleinstfahrzeugeVerordnung—eKFV. 2019. Available online: https:/ / www.gesetze-im-internet.de/ekfv/BJNR075610019.html (accessed on 22 February 2021).

10. Tack, A.; Klein, A.; Bock, B. E-Scooter in Deutschland. Ein datenbasierter Debattenbeitrag. 2019. Available online: https: //scooters.civity.de/ (accessed on 22 April 2021). 
11. Agora Verkehrswende. E-Tretroller im Stadtverkehr-Handlungsempfehlungen für Deutsche Städte und Gemeinden zum Umgang Mit Stationslosen Verleihsystemen. 2019. Available online: https://www.agora-verkehrswende.de/fileadmin/Projekte/ 2019/E-Tretroller_im_Stadtverkehr/Agora-Verkehrswende_e-Tretroller_im_Stadtverkehr_WEB.pdf (accessed on 10 May 2021).

12. Baek, K.; Lee, H.; Chung, J.-H.; Kim, J. Electric scooter sharing: How do people value it as a last-mile transportation mode? Transp. Res. Part D Transp. Environ. 2020, 90, 102642. [CrossRef]

13. Arendsen, K. Shared Mobility for the First and Last Mile: Exploring the Willingness to Share. 2019. Available online: http: / / resolver.tudelft.nl/uuid:9976ea22-07be-4674-b984-1a8f6563f0ee (accessed on 10 May 2021).

14. Arndt, W.-H.; Drews, F.; Langer, V.; Hertel, M.; Wiedenhöft, E. Integration von Ansätzen Geteilter Mobilität in Nachhaltigen Urbanen Verkehrsentwicklungsplänen (SUMP). Ein Themenleitfaden; Difu: Berlin, Germany, 2020. Available online: https://difu.de/ publikationen/2020/integration-von-ansaetzen-geteilter-mobilitaet-in-nachhaltigen-urbanen-verkehrsentwicklungsplaenen (accessed on 10 May 2021).

15. Held, M. Entwicklung von Handlungsempfehlungen für den Umgang mit elektrischer Mikromobilität in Städten am Beispiel Ludwigsburg; Technische Universität München: München, Germany, 2020.

16. Hollingsworth, J.; Copeland, B.; Johnson, J. Are e-scooters polluters? The environmental impacts of shared dockless electric scooters. Environ. Res. Lett. 2019, 14, 084031. [CrossRef]

17. Umweltbundesamt. E-Scooter Momentan Kein Beitrag zur Verkehrswende. 2020. Available online: https://www. umweltbundesamt.de/themen/verkehr-laerm/nachhaltige-mobilitaet/e-scooter\#aktuelles-fazit-des-uba (accessed on 10 March 2021).

18. James, O.; Swiderski, J.; Hicks, J.; Teoman, D.; Buehler, R. Pedestrians and e-scooters: An initial look at e-scooter parking and perceptions by riders and non-riders. Sustainability 2019, 11, 5591. [CrossRef]

19. Sikka, N.; Vila, C.; Stratton, M.; Ghassemi, M.; Pourmand, A. Sharing the sidewalk: A case of E-scooter related pedestrian injury. Am. J. Emerg. Med. 2019, 37, 180-1807. [CrossRef] [PubMed]

20. Yang, H.; Ma, Q.; Wang, Z.; Cai, Q.; Xie, K.; Yang, D. Safety of micro-mobility: Analysis of E-Scooter crashes by mining news reports. Accid. Anal. Prev. 2020, 143, 105608. [CrossRef] [PubMed]

21. König, A.; Gebhardt, L.; Schuppan, J.; Stark, K. A multi-perspective assessment of the introduction of e-scooter sharing concepts in Germany. Transp. Part D. This paper is accepted, but not publish yet.

22. Deutscher Städtetag. Mehr Sicherheit Durch Geringere Geschwindigkeit. 2020. Available online: https://www.staedtetag.de/ presse/pressemeldungen/mehr-sicherheit-durch-geringere-geschwindigkeit-eigenes-verkehrszeichen-notwendig (accessed on 5 March 2021).

23. Deutscher Städtetag. Nahmobilität Stärken-E-Tretroller in den Stadtverkehr Integrieren. 2019. Available online: https: //www.staedtetag.de/presse/pressemeldungen/nahmobilitaet-staerken-e-tretroller-in-den-stadtverkehr-integrieren (accessed on 5 March 2021).

24. Lime. Lime Annual Report 2020; Lime: San Francisco, CA, USA, 2021.

25. Mathew, J.; Liu, M.; Li, H.; Seeder, S.; Bullock, D. Analysis of E-Scooter Trips and Their Temporal Usage Patterns. ITE J. 2019, 89, $44-49$.

26. Portland Bureau of Transportation. 2018 E-Scooter Findings Report. 2019. Available online: https:/ /www.portlandoregon.gov / transportation/article/709719 (accessed on 22 March 2021).

27. Bürgerschaft Hamburg. E-Tretroller und StadtRAD; Bürgerschaft der Freien und Hansestadt Hamburg: Hamburg, Germany, 2019.

28. Forum bikesharing Schweiz. Was bedeutet die geteilte Mikromobilität für das Schweizer Verkehrssystem? In Forum Bikesharing Schweiz; Infoletter, Ballo, L., Wenger, A., Eds.; Forum bikesharing Schweiz: Bern, Switzerland, 2020; Volume 11.

29. Badia, H.; Jenelius, E. Shared e-Scooter Micromobility: A Review of Travel Behavior, Sustainability, Infrastructure, Safety and Policies. 2021. Available online: https://www.researchgate.net/publication/349763087_Shared_e-scooter_micromobility_A_ review_of_travel_behavior_sustainability_infrastructure_safety_and_policies (accessed on 10 April 2021). [CrossRef]

30. Reintjes, D. Sind E-Scooter eine Erfolgsgeschichte? Wirtschaftswoche 28.10.2020. Available online: https://www.wiwo.de/ unternehmen/dienstleister/analyse-in-grafiken-sind-e-scooter-eine-erfolgsgeschichte/26565066.html (accessed on 5 November 2020).

31. Mathew, J.K.; Liu, M.; Bullock, D.M. Impact of weather on shared electric scooter utilization. In Proceedings of the 2019 IEEE Intelligent Transportation Systems Conference (ITSC), Auckland, New Zealand, 27-30 October 2019; pp. $4512-4516$.

32. Krauss, K.; Scherrer, A.; Burghard, U.; Schuler, J.; Burger, A.M.; Doll, C. Sharing Economy in der Mobilität-Potenzielle Nutzung und Akzeptanz Geteilter Mobilitätsdienste in Urbanen Räumen in Deutschland. Working Paper Sustainability and Innovation. 2020. Available online: https:/ / www.isi.fraunhofer.de/content/dam/isi/dokumente/sustainability-innovation/2020/WP-06 -2020_Sharing_\%20Economy\%20_in_der_Mobilit\%C3\%A4t_Krauss_Scherrer_Burghard_Schuler_Burger_Doll.pdf (accessed on 22 March 2021).

33. Zou, Z.; Younes, H.; Erdogan, S.; Wu, J. Exploratory Analysis of Real-Time E-Scooter Trip Data in Washington, D.C. Transp. Res. Rec. J. Transp. Res. Board 2020, 2674, 036119812091976. [CrossRef]

34. 6t-Bureau de Recherche. A Sound Launch for Micromobility Services in the UK the Challenge of Parking. 26 October 2020. Available online: https:/ / 6-t.co/en/etudes/lenjeu-du-stationnement-pour-le-developpement-des-services-de-micromobiliteau-royaume-uni/ (accessed on 5 November 2020). 
35. Austin Public Health. Dockless Electric Scooter-Related Injuries Study. 2019. Available online: https:/ / www.austintexas.gov/ sites/default/files / files/Health/Epidemiology/APH_Dockless_Electric_Scooter_Study_5-2-19.pdf (accessed on 20 April 2021).

36. Hanack, J. Verleihstation: Erster Jelbi-Hub in Spandau Eröffnet; Berliner Morgenpost: Berlin, Germany, 2020.

37. Stadtportal Hamburg. Angebot an E-Rollern in Poppenbüttel und Berne Wächst. Available online: https://www.hamburg.de/emobilitaet/13111658/voi-und-hochbahn/ (accessed on 21 March 2021).

38. Nobis, C.; Kuhnimhof, T. Mobilität in Deutschland-MiD Ergebnisbericht. Studie von Infas, DLR, IVT und Infas 360 im Auftrag des Bundesministeriums für Verkehr und Digitale Infrastruktur. 2018. Available online: http:/ /www.mobilitaet-in-deutschland. de/pdf/MiD2017_Ergebnisbericht.pdf (accessed on 20 April 2021).

39. Follmer, R.; Gruschwitz, D. Mobility in Germany-Short Report. 2019. Available online: http://www.mobilitaet-in-deutschland. de/pdf/MiD2017_ShortReport.pdf (accessed on 20 April 2021).

40. Nobis, C.; Köhler, K. Mobilität in Deutschland-MiD: Nutzerhandbuch. 2018. Available online: http://www.mobilitaet-indeutschland.de/pdf/MiD2017_Nutzerhandbuch.pdf (accessed on 20 April 2021).

41. BMVI. MiD 2017-Mobilität in Deutschland. Mikrodaten (Public Use File). Available online: www.clearingstelle-verkehr.de (accessed on 20 April 2021).

42. BMVI. Regionalstatistische Raumtypologie (RegioStaR). Available online: https://www.bmvi.de/SharedDocs/DE/Artikel/G/ regionalstatistische-raumtypologie.html (accessed on 10 March 2021). 